\title{
Torsión de un apéndice epiploico Reporte de 2 casos: Características ecográficas y tomográficas
}

\author{
Daniel Sayago-Castro ${ }^{1}$
}

\begin{abstract}
Resumen: El infarto de una apéndice epiploica produce un proceso inflamatorio que se localiza en la región del colon afectada así como a la porción correspondiente del omento mayor. La apendagitis epiploica tiene hallazgos sonográficos y de TAC característicos los cuales contribuyen al diagnostico rápido y por lo tanto ayudan con el manejo del paciente. Se presentan aquí dos casos:
\end{abstract}

Recibido: 19 de julio, 2001

Aceptado para publicación: 11 deenero, 2002

Los apéndices epiploicos son estructuras adiposas que miden entre 5 y $50 \mathrm{~mm}$, que protruyen de la superficie serosa del colon desde el ciego hasta la unión del recto sigmoides. La torsión, la isquemia o la inflamación de los apéndices epiploicos son eventos que ocurren espontáneamente y el cuadro clínico se denomina apendagitis. Esta condición se manifiesta con dolor abdominal localizado que se puede confundir con una apendicitis o una diverticulitis y su diagnóstico la mayoría de las veces solo se hace durante la cirugía.

L a ecografía (ultrasonido) como ya se sabe es una herramienta muy efectiva en manos del radiólogo, para la exploración del abdomen sin necesidad de abrirlo. Esta herramienta permite la realización de un examen rápido, barato y dinámico que se puede repetir cuantas veces se considere necesario; pero requiere dedicación, habilidad y experiencia. Es así como ha contribuido no solo al diagnóstico y curación de pacientes sino también ha ayudado a comprender la incidencia y la evolución natural de muchas condiciones abdominales como la torsión del apéndice epiploico 0 apendagitis.

Esta entidad patológica tiene escasos reportes en los anales médicos y es así como algunos cirujanos de gran trayectoria mencionan solo uno o dos casos dentro de su experiencia quirúrgica. Con la llegada de la ecografía y la T.A.C. esta incidencia ha cambiado desde el punto de imágenes ya que algunos grupos han llegado a reportar hasta 14 casos de

A breviaturas: TAC, Tomografía Axial Computarizada; HCG, Hospital Calderón Guardia.

1 Departamento de Imágenes Clínica Santa Catalina. Desamparados. Departamento de imágenes Clínica Jiménez Nuñez; CCSSS.

Correspondencia: Daniel Sayago Castro. 2294 - 2100. dany_say@yahoo.com

A M C, enero-marzo 2002, vol 44 (1) apendagitis, como lo hicieron Rioux y $L$ angis ${ }^{1}$, en un periodo de 18 meses. Esta es una incidencia muy alta en una patología poco común. Tanto la ecografía como la T.A.C. han demostrado la auto limitación de la apendagitis muchas veces diagnosticada como cuadros de diverticulitis.

\section{Reporte de casos}

Caso $\mathrm{N}^{\circ} 1$

Paciente femenina de 65 años que fue referida al Servicio de Radiodiagnóstico del H.C.G. con un cuadro de dolor abdominal localizado en el flanco derecho de mas de 48 horas de evolución. Negaba pérdida del apetito, nauseas, vómitos, diarrea, hematoquexia o melena. Solo manifestaba un dolor exquisito a la pal pación del flanco derecho a unos $10 \mathrm{~cm}$ por encima del área cecal con rebote positivo.

L a ecografía se realizó sin preparación especial, y mostró una imagen de aspecto nodular, ovoide, que midió 25.2 x 15.9 x $21.4 \mathrm{~mm}$ con una ecogenicidad muy similar a los tejidos circundantes, bien definida con cambios inflamatorios con un halo hipoecoico nítido localizada en el colon ascendente en la cara anteromedial bajo la pared abdominal unos $10 \mathrm{~cm}$ por encima del ciego.(figura 1)

La T.A.C. se realizó después de administrar un enema con medio de contraste hidrosoluble diluido y se hicieron cortes finos con intervalos de $5 \mathrm{~mm}$ sobre el área de interés, se demostró una lesión ovoide de 21.6 x $14.2 \mathrm{~mm}$ con un coeficiente de atenuación correspondiente a grasa con una importante reacción inflamatoria a su alrededor sin colecciones; justo en la zona explorada ecográficamente y coincidente con el punto de mayor dolor en la paciente.(figura 2)

La paciente fue manejada de manera conservadora y se le realizó una ecografía tres meses después sin que se demostrase al teraciones en esta zona. 


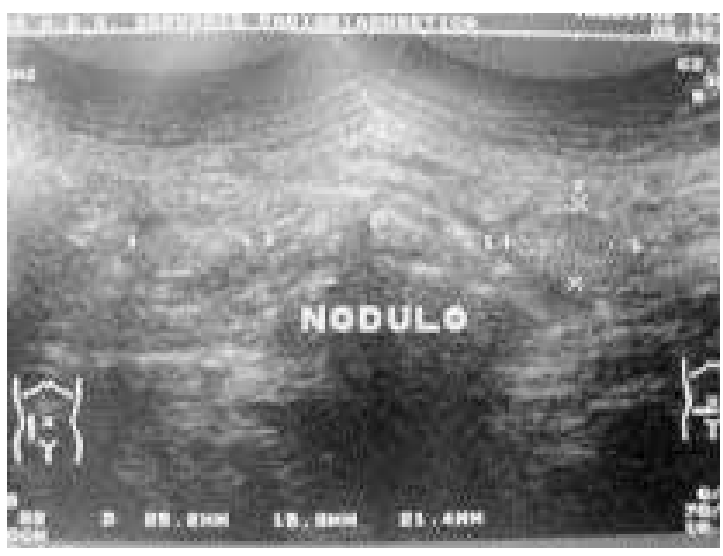

Figura 1

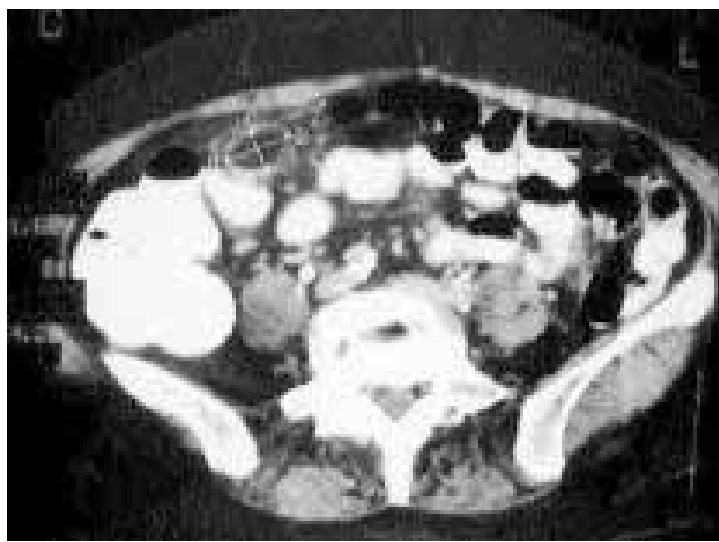

Figura 2

\section{Caso $\mathrm{N}^{\circ} 2$}

Paciente masculino de 49 años que consultó al servicio de emergencias por dolor de 3 días de evolución localizado en la fosa ilíaca derecha que había ido en aumento. A sociaba nauseas y al examen físico había rebote positivo en la fosa ilíaca derecha.

Se realizó una ecografía que mostró una imagen ovoide de bordes difusos relacionado con edema importante de los tejidos circundantes y escasa cantidad de líquido perilesional localizada en el ciego en la cara anteromedial directamente bajo la pared abdominal. La lesión se podía definir mejor con un halo hipoecoico, en los cortes transversales que en los longitudinales. Dicha imagen ovoide midió $47 \times 21$ x 23 mm. (figura 3)

En la exploración quirúrgica se encontró un apéndice epiploico de $5 \mathrm{~cm}$ torsionado con necrosis y cambios inflamatorios locales.

\section{Discusión}

L a torsión de un apéndice epiploico puede dar una apariencia ecográfica tan parecida a la diverticulitis, que su diferenciación la hace difícil ${ }^{1,2}$. La grasa inflamada/infartada del

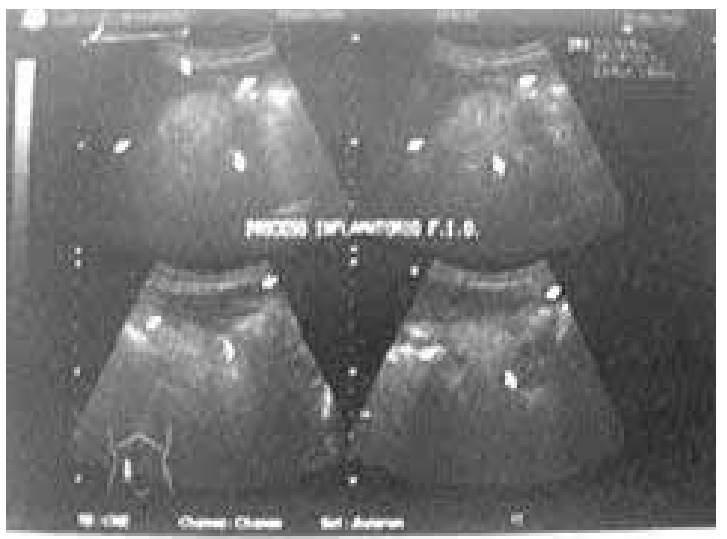

Figura 3

apéndice, aparece como un área sombreada de aumento de la ecogenicidad al lado del margen colónico, simulando un divertículo inflamado. Los cambios inflamatorios perientéricos regionales son sin embargo, mínimos y la clínica sistémica también ${ }^{2,5}$. Los apéndices colónicos no inflamados no son visibles, excepto cuando existe ascitis, donde se ven como focos ecogénicos espaciados uniformemente a lo largo de los márgenes del colon ${ }^{1,5}$.

En conclusión la apendagitis se puede diagnosticar por ecografía y complementar con la T.A.C. y según los hallazgos se puede tomar una conducta conservadora en los pacientes con dolor localizado en al guno de los flancos sin síntomas sistémicos o elevación anormal del recuento de células blancas 3,4, 5 .

\section{Abstract}

A cute infarction of an appendix epiploica results in an inflammatory process localized to the affected portion of the colon and the adjacent greater omentum. The primary epiploic apendagitis has fairly characteristic US and CT features that contribute to a rapid diagnosis and help in the hand ling of the patient.

We present here two cases recently seen by the author that illustrate this condition.

\section{Referencias}

1 Rioux M, L angis P. Primary epiploic appendagitis: clinical, US, and CT findings in 14 cases. Radiology 1994; 191:523-526.

2 Julien B.C.M. Puylaert. When in doubt, sound it out. Radiology 1994; 191:320-321.

3 K elvin Danielson, Mark M. Chermin, et cols. Case Report. Epiploic A ppendicitis: CT Characteristics. Journal of computer assisted tomography 10 (1): 142-143. January/february. 1986.

4 Patrick M. Rao, Jack Wittenberg, J. Nash Lawrason. Primary Epiploic Appendagitis: Evolutianary Changes in Ct appearance. Radiology 1997; 204:713-717.

5 Gary G. Ghahremani, E. M aureen White, Frederick L. Hoff. A ppendices Epiploicae of the colon: Radiologic and Pathologic features. Radiographics 1992; 12:59-77. 